\title{
CONCISE
}

PUBLICATIONS

\section{Resistance to Symptomatic Insulin Reactions after Fasting}

\author{
Ernst J. Drenick, lia C. Alvarez, Gabor C. Tamasi, and \\ ARNold S. BRickMan \\ From the Medical Service and Research, Veterans Administration Wadsworth \\ Hospital Center, Los Angeles, California 90073, and the Department of \\ Medicine, University of California at Los Angeles School of Medicine, \\ Los Angeles, California 90024
}

A B S T R A C T This study was carried out to determine if, in fasting, an adaptation to utilization of ketones could prevent cerebral dysfunction during periods of acute, insulin-induced glucopenia.

In the course of standard insulin tolerance tests $(0.1-$ $0.2 \mathrm{U} / \mathrm{kg}$ ), nine obese subjects manifested frank hypoglycemic reactions resulting in an increase in urinary catecholamine excretion from 61 to $113 \mu \mathrm{g} / 24 \mathrm{hr}(P<$ 0.01 ). After fasting 2 months, administration of weightadjusted doses of insulin produced identical maximum insulin concentrations and disappearance curves. However, no insulin reactions nor significant rises in catecholamine excretion occurred despite equal extent and rate of glucose fall. Glucose concentrations as low as 0.5 mmoles/liter $(9 \mathrm{mg} / 100 \mathrm{ml}$ ) failed to precipitate hypoglycemic reactions. During the postfast insulin tolerance tests, mean plasma 2-hydroxybutyrate ( $\beta$-OHB) decreased from 8.02 to 6.69 mmoles/liter $(P<0.01)$. In another five fasting subjects tested, the $\mathrm{A}-\mathrm{V}$ difference for $\beta$-OHB across brain increased progressively from 0.21 to 0.70 mmoles/liter whereas across the forearm no consistent uptake could be demonstrated. Simultaneously, the $\mathrm{A}-\mathrm{V}$ difference across the brain for glucose decreased from 0.24 to 0.07 mmoles/liter of plasma.

In addition to insulin-induced suppression of hepatic ketogenesis, the augmented cerebral ketone uptake during insulin hypoglycemia contributes to the net fall in plasma $\beta$-OHB. Ketoacids, extracted by the fast-adapted

Received for publication 2 September 1971 and in revised form 11 July 1972. brain, supplant glucose as a metabolic substrate preventing overt hypoglycemic reactions during acute glucopenia.

\section{INTRODUCTION}

It has been demonstrated that in prolonged fasting, ketoacids are extracted from blood passing through the brain (1) and that the convulsant dose of insulin has to be increased fivefold in order to produce the same incidence of convulsions in fasted as in nonfasted mice (2). The present study was carried out to elucidate if the adaptation to utilization of ketoacids can render the brain of fasting humans resistant to the ill effects of glucose privation and if enhanced cerebral utilization of 2-hydroxybutyrate $(\beta-\mathrm{OHB})^{\mathbf{1}}$ can be demonstrated during acute glucopenia.

\section{METHODS}

Obese men weighing $240-403 \mathrm{lb}$. were studied on a metabolic balance ward. Base line insulin tolerance tests were administered in the postabsorptive state with the subject at bed rest. Repeat tests were carried out in nine subjects after a minimum of 60 days of fasting which had resulted in a mean weight loss of $73 \mathrm{lb}$. Regular crystalline insulin was injected intravenously. The doses ranged from 0.1 to 0.2 $\mathrm{U} / \mathrm{kg}$ body weight. Four subjects weighing more than 375 lb. were given the lower $(0.1 \mathrm{U} / \mathrm{kg})$ dose. The postfast dose was decreased in proportion to weight loss but for each subject the $U / \mathrm{kg}$ body weight ratio was kept constant. Multiple blood samples were drawn during a $2 \mathrm{hr}$ period from a deep forearm vein via an indwelling catheter. Blood

\footnotetext{
${ }^{1}$ Abbreviation used in this paper: $\beta$-OHB, $\beta$-hydroxybutyrate.
} 


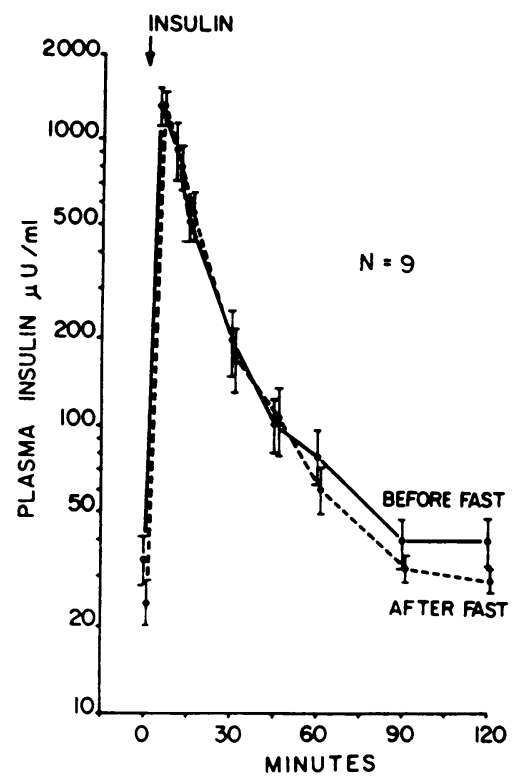

Figure 1 Plasma concentrations and disappearance curves for administered insulin before and after prolonged fasting $(\mathrm{N}=9$, means $\pm \mathrm{SEM})$.

pressure, pulse rate, and subjective symptoms were monitored. Plasma insulin levels were determined by the method of Yalow and Berson (3). Plasma glucose (4), serum free fatty acids (5), and $\beta$-OHB (6) were measured. Each blood sample was divided into two portions and duplicate determinations were carried out on each. The recorded data are the means of all measurements. Because of rapid and extensive changes in substrate concentrations only single samples were withdrawn for each timed interval. Catecholamines (7) were measured in the urine.

In five additional subjects, insulin tolerance tests were attempted after 45-60 days of fasting and blood samples were drawn simultaneously from the radial artery, the internal jugular, and a deep antecubital vein through percutaneous indwelling catheters. This was done to determine if more $\beta-\mathrm{OHB}$ is extracted from blood passing through the brain than through the forearm. In three of these subjects $0.2 \mathrm{U}$ of insulin $/ \mathrm{kg}$ body weight was injected and in two subjects who weighed more than $400 \mathrm{lb}$., $0.1 \mathrm{U} / \mathrm{kg}$ was given.

\section{RESULTS}

Signs and symptoms of hypoglyccmic reactions. Before fasting, the clinical responses to insulin in the nine subjects ranged from the usual signs and symptoms, sweating, nervousness, tachycardia, and rising blood pressure to constricting chest pain and mental confusion. The severity varied from moderate to marked. Subjects experiencing the most rapid and extensive blood sugar decrements had a greater number of abnormal symptoms and signs. An average of $30 \mathrm{~min}$ elapsed between the insulin injection and the onset of symptoms which coincided with the nadir in plasma glucose concentration.
After the fast, the same nine subjects had no insulin reactions.

Changes in insulin levels. To determine if the calculated doses of injected insulin were equivalent before and after weight loss, the maximum concentrations and disappearance slopes were plotted semilogarithmically (Fig. 1). At the 10 min interval of the pre- and postfast
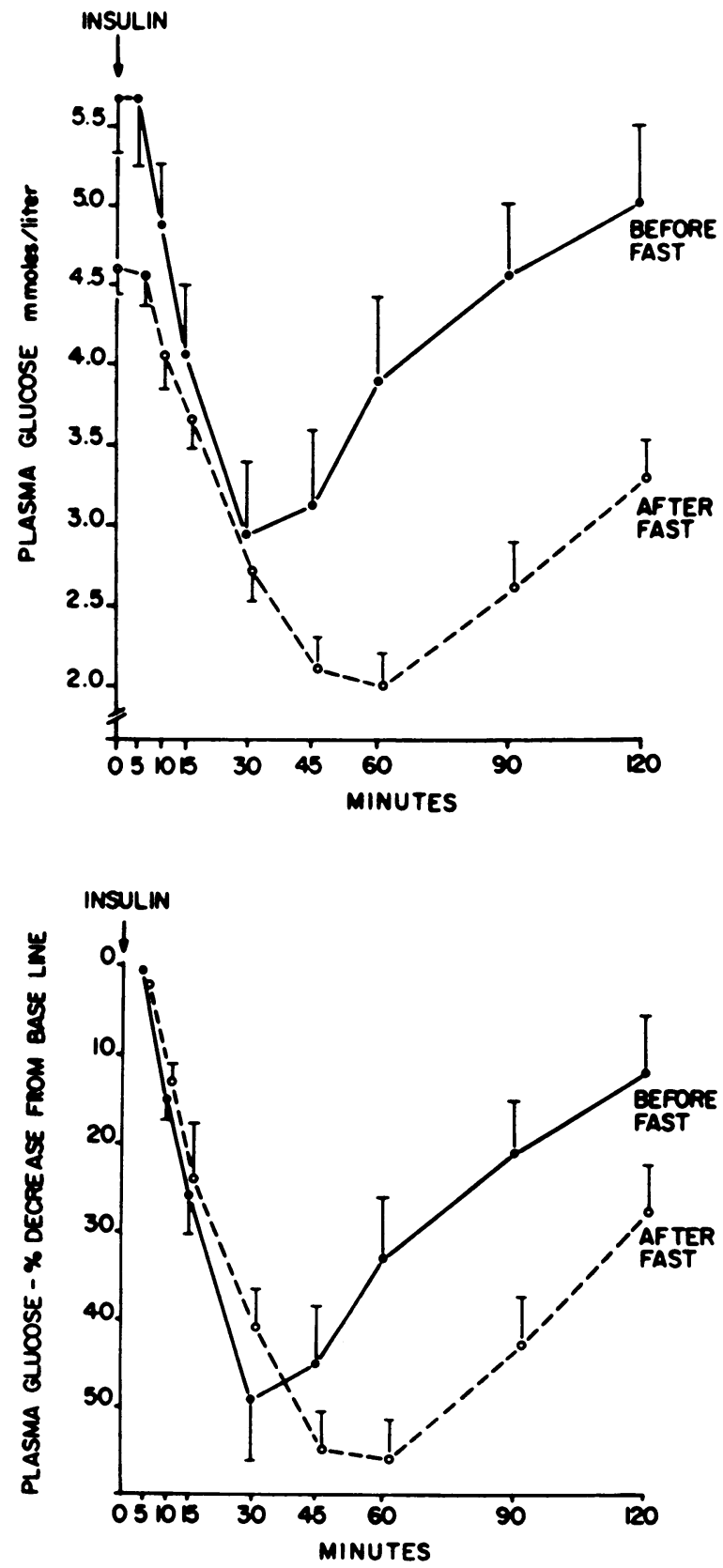

Figure 2 Plasma glucose concentrations and per cent changes from base line after insulin; before and after prolonged fasting $(\mathrm{N}=9$, means $\pm \mathrm{SEM})$. 
tests, when insulin distribution in the extracellular fluid space was presumed to be complete and uniform, plasma concentrations of the injected insulin were identical and, subsequently, the concentrations for all collection intervals up to $90 \mathrm{~min}$ were the same. The per cent fall per minute on semilog scale, (k-value) for the 10- to 30-min interval was found to be 8.53 and 9.35 , respectively for the prefast and postfast tests. The difference between the two values was not statistically significant $(P>0.1)$.

Changes in substrate concentrations. The absolute changes in plasma glucose levels and per cent changes from base line are represented in Fig. 2. The maximum mean decrement in glucose levels after insulin was 2.72 mmoles/liter before and $2.50 \mathrm{mmoles} /$ liter after the fast period. A nadir in mean glucose concentrations of 2.94 mmoles/liter was reached at $30 \mathrm{~min}$ before the fast. A mean low point of 2.11 mmoles/liter was attained at the 45 min interval of the test after fasting. Postfast, in four subjects the nadir actually occurred at $60 \mathrm{~min}$ and in one subject at the $90 \mathrm{~min}$ interval. The most extensive fall in glucose concentration at the $45 \mathrm{~min}$ interval in any of the subjects was $4.33 \mathrm{mmoles} / \mathrm{liter}$ and the lowest glucose concentration after insulin was $0.50 \mathrm{mmoles} / \mathrm{liter}$. The per cent decreases in plasma glucose at the $30 \mathrm{~min}$ interval, the point in time when insulin reactions occurred during the prefast test were very similar before and after fasting, that is, 49.9 and $40.7 \%$, respectively. However, the postfast decline continued in a linear fashion to the 45 min interval, reaching a low point of $54.5 \%$ below base line without hypoglycemic manifestations. In order to evaluate whether the rates of fall before and

\section{TABLE I}

Changes in A-V Substrate Differences Across Brain* in Fasting Obese Men during Insulin Tolerance Tests

\begin{tabular}{lcccccc}
\hline \multicolumn{7}{c}{ Minutes after insulin } \\
\cline { 2 - 7 } & 0 & 15 & 30 & 45 & 60 & 120 \\
\hline$\beta$-OHB & & & & & \\
C. J. & 0.21 & 0.54 & 0.70 & 0.86 & 0.66 & 0.88 \\
W. D. & 0.02 & 0.61 & 0.88 & 0.73 & 0.61 & 1.02 \\
J. P. & 0.25 & 0.45 & - & - & 0.35 & - \\
J. M. & 0.36 & - & - & - & - & - \\
J. G. & - & 0.46 & 0.46 & 0.34 & - & 0.68 \\
Mean & 0.21 & 0.52 & 0.68 & 0.70 & 0.54 & 0.86 \\
SEM & $\pm 006 ;$ & \pm 0.035 & \pm 0.12 & \pm 0.12 & \pm 0.094 & \pm 0.098 \\
Glucose & & & & & & \\
C. J. & 0.28 & 0.28 & 0.22 & 0.17 & 0.06 & 0.00 \\
W. D. & 0.17 & 0.44 & -0.11 & 0.05 & 0.33 & 0.22 \\
J. P. & 0.03 & 0.00 & 0.28 & 0.00 & 0.61 & - \\
J. M. & 0.18 & - & - & - & - & - \\
J. G. & - & 0.44 & 0.00 & 0.06 & 0.22 & 0.11 \\
Mean & 0.24 & 0.29 & 0.10 & 0.07 & 0.20 & 0.11 \\
SEM & \pm 0.035 & \pm 0.102 & \pm 0.061 & \pm 0.031 & \pm 0.115 & \pm 0.06 \\
\hline
\end{tabular}

The release of a substrate is denoted by a minus sign.

* mmoles/liter plasma.

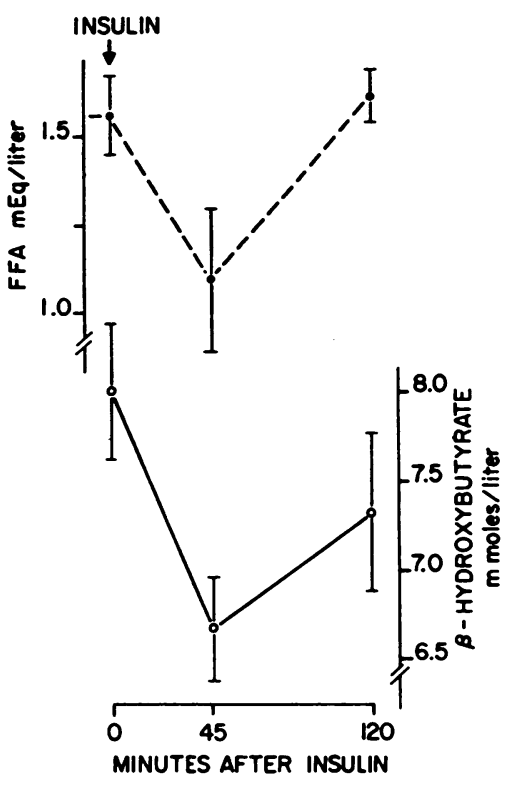

Figure 3 Changes in plasma FFA and $\beta$-OHB concentrations during the postfast insulin tolerance test.

after fasting were different, the disappearance curves were plotted semilogarithmically. The slopes exhibited a linear progression between the $5 \mathrm{~min}$ and the $30 \mathrm{~min}$ interval after insulin administration. Thus, $\mathrm{k}$-values expressing the per cent fall of plasma glucose per minute, could be calculated. Insulin sensitivity, as implied by the $\mathrm{k}$-value for the prefast test, was 2.91 and for the postfast test 2.21. By statistical analysis (paired $t$ test), these two values were not significantly different $(P>0.1)$. Initially, plasma glucose returned to basal levels within 90 to $120 \mathrm{~min}$ after insulin but failed to return to the pretest base line level up to the 2 hour interval in the postfast test.

Before the fast period serum free fatty acids (FFA) levels decreased slightly but significantly from base line after the administration of insulin but rose again to original concentrations simultaneously with the disappearance of the injected insulin from the plasma. With fasting, FFA levels had increased twofold but the response pattern to injected insulin was similar at the end of fasting. The transient fall was significant $(P<0.05)$ and the restoration to base line levels was complete at the $2 \mathrm{hr}$ interval (Fig. 3). The per cent decrease from base line levels was slightly greater after fasting, demonstrating that the antilipolytic effect of insulin had remained intact.

Before fasting $\beta$-OHB levels in the serum were low (mean 0.14 mmoles/liter) and these decreased to 0.09 mmoles/liter $45 \mathrm{~min}$ after insulin. With fasting the expected increases occurred, with peak concentrations ranging from 6.08 to 14.13 mmoles/liter (Fig. 3). The mean 


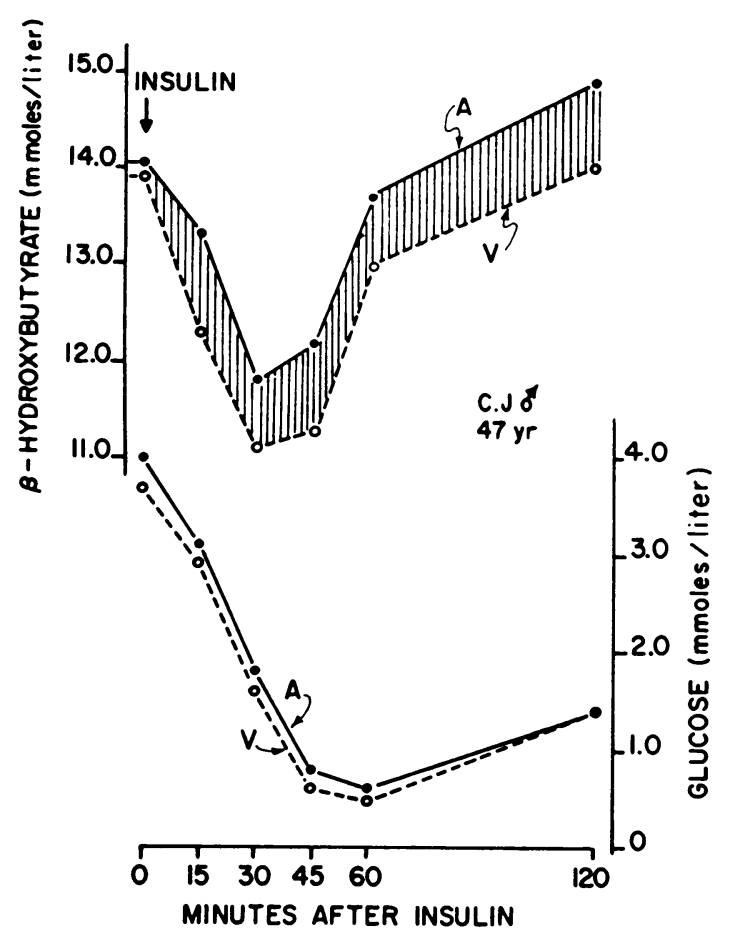

Figure $4 \mathrm{~A}-\mathrm{V}$ differences during an insulin tolerance test after a 50 day fast ( $A$, artery; $\mathrm{V}$, internal jugular vein).

for the nine subjects was $8.02 \pm 0.37$ mmoles/liter. The fall after insulin to a mean of 6.72 mmoles/ liter was significant $(P<0.01)$. This level was reached at $30 \mathrm{~min}$ and persisted to the $45-\mathrm{min}$ intervals. $2 \mathrm{hr}$ after insulin the mean concentration had not returned to base line levels although the difference between the $45 \mathrm{~min}$ and the $2 \mathrm{hr}$ level was not statistically significant. In three subjects the 2 -hr levels were actually higher than initially.

Arterial-internal jugular vein differences for $\beta-O H B$ and glucose. In Table I the concentrations for $\beta-\mathrm{OHB}$ and glucose in arterial and internal jugular vein blood are recorded. Base line values were measured in five sub-

TABLE II

Changes in A-V Differences of Plasma $\beta-O H B$ Concentrations Across the Forearm in Fasting Obese Men during Insulin Tolerance Tests*

\begin{tabular}{lrrrrrr}
\hline \multicolumn{7}{c}{ Minutes after insulin } \\
\cline { 2 - 7 } & \multicolumn{1}{c}{0} & 15 & 30 & 45 & 60 & 120 \\
\hline B-OHB & & & & & & \\
C. J. & -0.141 & 0.351 & 0.70 & - & -0.293 & 0.074 \\
W. D. & 0.085 & 0.265 & 0.824 & 0.447 & 0.447 & 0.595 \\
J. P. & -0.357 & 0.224 & -0.358 & -0.173 & -0.259 & - \\
J. M. & 0.066 & - & - & - & - & - \\
J. G. & 0.229 & -0.137 & 0.046 & 0.159 & -0.079 & 0.041 \\
Mean & -0.115 & 0.177 & 0.146 & 0.144 & -0.046 & 0.187 \\
SEM & \pm 0.085 & \pm 0.108 & \pm 0.246 & \pm 0.179 & \pm 0.171 & \pm 0.207 \\
\hline * mmoles/liter & & & & & &
\end{tabular}

jects but because of technical difficulties full sample collections could be obtained in only two and partial collections in three subjects. Mean $\mathrm{A}-\mathrm{V}$ differences for $\beta$-OHB were $0.21 \mathrm{mmoles} / \mathrm{liter}$ before insulin rising to $0.70 \mathrm{mmoles} /$ liter of plasma at the $45 \mathrm{~min}$ interval. A markedly enhanced uptake, more than three times greater than initially, persisted to the end of the $2 \mathrm{hr}$ test. Venous blood samples drawn simultaneously from a deep antecubital vein showed variable $A-V$ differences and in some instances a slightly higher concentration in venous than in arterial blood (Table II).

Mean A-V differences for glucose tended to decrease with progressive hypoglycemia reaching a low point at the $45 \mathrm{~min}$ interval. A representative sequence of changes for one subject is shown in Fig. 4.

Catecholamine excretion. The urinary catecholamines, measured in five subjects of the group, increased from a mean of $55 \pm 13 \mu \mathrm{g} / 24 \mathrm{hr}$ on the day before, to $107 \pm 21$ $\mu \mathrm{g} / 24 \mathrm{hr}$ on the day of the insulin tolerance test. This increase was significant $(P<0.01)$ and is in accord with the responses reported in healthy normal subjects (8). At the end of the fast period the urinary catecholamines on the day before the test measured $56 \pm 11 \mu \mathrm{g} / 24$ $\mathrm{hr}$ and $81 \pm 10 \mu \mathrm{g} / 24 \mathrm{hr}$ on the test day. This difference proved to be not significant $(P>0.1)$. Increments in catecholamine excretion were then correlated to various expressions of change in glucose concentrations. Before fasting, the zero order correlation coefficient for the absolute glucose nadir was $0.854(r>0.95)$, for per cent fall of glucose 0.742 and for $\mathrm{k}$-values 0.544 . In contrast, after fasting, the respective coefficients were $0.684,0.707$, and 0.135 , suggesting a diminishing correlation. Because of the small sample size this trend could not be proven to be significant, using the $Z$-statistic to test for a difference between correlation coefficients.

\section{DISCUSSION}

Under normal circumstances the energy requirements of the brain are supplied almost exclusively by oxidation of glucose. In prolonged fasting, the brain adapts to the reduction in available glucose and to the abundance of ketones by an enhanced uptake of the latter. An arteriovenous $\beta$-OHB difference across the brain of fasting humans of 0.34 mmoles suggested efficient extraction by intracranial tissues (1). In the brain of fasting rats, increased activity of $\beta$-OHB dehydrogenase was demonstrated in one study (9) but not in another (10). Brains of patients dying of ketoacidosis were found to have increased quantities of enzymes involved in the metabolism of ketones (11). It had also been shown that ketoacids can replace glucose when tissue from ketotic rats is incubated with these substrates (12-14). Although it had been demonstrated that fasted mice were more resistant to the convulsant effect of insulin (2) it was not known 
if the fasted human brain could tolerate an acute fall in glucose concentrations to very low levels without the development of hypoglycemic manifestations.

Satisfactory evidence for such an adaptation had to be sought in subjects who had actually experienced symptomatic hypoglycemic reactions before fasting but proved insensitive to the stress of equally severe hypoglycemic episodes after fasting. Davidson and Albrink (15) had noted that the blood sugar-lowering effect of insulin in overweight subjects was inversely proportional to the degree of obesity. In accord with these observations, overt insulin reactions occurred in only 12 of 51 massively obese subjects even through insulin doses of up to $0.2 \mathrm{U} / \mathrm{kg}$ of body weight were used.

The experimental conditions during the prefast and postfast tests were equivalent with regard to maximum insulin concentrations and disappearance rates. An unaltered lipolytic effect of the injected insulin was demonstrated by equivalent percentage falls in serum FFA before and after the fast. The per cent fall in blood sugar levels up to $30 \mathrm{~min}$ after insulin was slightly less after fasting but it was not significantly different from prefast tests. These results are in agreement with the observations of others who performed insulin tolerance tests in obese subjects after 14-day fasts (16). The hypoglycemic effect of insulin after the fast was more prolonged producing a nadir at the $60 \mathrm{~min}$ interval. It appears unlikely therefore, that the slightly more sluggish decline of glucose after fasting could have been responsible for the observed reduction in adrenergic responses. One subject, not included in this group, was inadvertently given the same dose of insulin prefast and postfast. The amount of insulin $/ \mathrm{kg}$ and the extent and rate of glucose fall were considerably greater than prefast. Nonetheless, no insulin reaction occurred although this subject had had a violent reaction prefast.

It could be argued that fasting may have induced a degree of resistance to adrenergic stimuli in the receptor tissues but this possibility appears to be less likely in view of the fact that manifestations of a primary disturbance of cerebral function, such as confusion, were abolished as well. These latter manifestations are presumed to result from direct interference with brain cell metabolism rather than from epinephrine release.

To make a plausible argument for the substitution of ketones as a central nervous system fuel in place of glucose a net decrease in plasma ketone levels as well as an enhanced extraction of ketones from blood passing through the brain should be demonstrable. The observed initial fall in serum $\beta-\mathrm{OHB}$ levels after insulin injection could be explained in several ways. First, inhibition of lipolysis may result in a relative lack of substrate for hepatic ketogenesis. Secondly, as shown by Foster, insulin may inhibit ketogenesis by a direct effect upon the liver (17).
Third, fuel-starved tissues, peripheral as well as brain, may utilize more $\beta$-OHB (18). Finally, a combination of any of the three factors may be operative.

During the initial phase, that is up to the 30 -min interval, the reduction in FFA levels may have contributed to the lowering in plasma $\beta-\mathrm{OHB}$ although observations by Bieberdorf, Chernick, and Scow indicated that insulin suppressed ketogenesis independent of plasma FFA levels (19). However at the $2 \mathrm{hr}$ interval, $\beta$-OHB levels remained depressed in several subjects while at the same time serum FFA levels had returned to the original elevated fasting levels. This dissociation suggests that a lack of precursor substrate for ketogenesis was not involved in the lowering of $\beta$-OHB levels, at least not during the latter phase of postinsulin hypoglycemia. The base line $\mathrm{A}-\mathrm{V}$ differences obtained in the fasting subjects of this group compare well with the results obtained by Owen et al. (1). It had been stated by Hawkins, et al. (10), Williamson et al. (11), and Gottstein et al. (20) that cerebral uptake of $\beta$-OHB is proportional to the concentration in the circulating blood. During steady-state conditions for glucose and $\beta-\mathrm{OHB}$ concentrations this relationship appears to be confirmed. However, in this study, the increasing A-V differences in the early postinsulin phase-whereas plasma glucose and $\beta$-OHB levels fall-suggest that under these circumstances uptake is not exclusively a function of plasma substrate concentration. The threefold increases in $\mathrm{A}-\mathrm{V}$ differences across the brain with progressive hypoglycemia contrast with a simultaneous threefold diminution in $\mathrm{A}-\mathrm{V}$ differences of blood glucose. The increase in cerebral $\beta$-OHB extraction appeared inordinately high when one attempts to relate it to reported rates of $\mathrm{O}_{2}$ uptake. A satisfactory explanation for this phenomenon is not at hand. The possibility should be considered that not all of the $\beta$-OHB $\mathrm{A}-\mathrm{V}$ difference reflects terminal oxidation. Alternate pathways with conversion to amino acids or glucogenic intermediates or removal into cerebrospinal fluid (21) could contribute to the A-V difference. However, an enhanced cerebral consumption of substrates other than glucose would seem to be likely in glucopenia. It had been shown by Eisenberg and Seltzer (22) that cerebral glucose utilization decreased during insulin hypoglycemia while $\mathrm{O}_{2}$ consumption rose significantly. They also demonstrated that the rate of blood flow did not change during the hypoglycemic phase so that the increasing A-V difference of $\beta-\mathrm{OHB}$ in this study is likely to reflect increased cerebral uptake. While Balasse and Havel (18) postulated that insulin enhances $\beta$-OHB utilization by peripheral tissues this could not be demonstrated on the basis of $\mathrm{A}-\mathrm{V}$ differences across the forearm of the subjects in this group. In fact, some of the venous $\beta$-OHB levels were slightly higher than the arterial concentration indicating, perhaps, conversion of acetoacetate to $\beta-\mathrm{OHB}$ 
in peripheral tissue. Similar findings had been reported by Owen and Reichard (23). The lack of uptake of $\beta$-OHB by forearm tissue vs. enhanced uptake by cerebral tissue constitutes a further argument in favor of the hypothesis that in fasting and particularly during acute glucopenia glucose is replaced by ketones as a fuel for the central nervous system.

The data in this study do not permit a definite explanation for the lagging return to normal of lowered glucose levels. One might speculate that in the absence of a significant catecholamine response in the adapted subject, hepatic glycogenolysis is depressed. In addition, it is conceivable that restoration of normal glucose levels was delayed because hepatic glycogen stores, after prolonged fasting, may be reduced to some degree. Finally, it may be possible that in the presence of ample ketones the stimulus for gluconeogenesis is diminished.

Of interest is the observation that the effect of large doses of exogenous insulin upon glucose disposal and lipolysis was virtually unaltered after fasting. This is surprising in view of the commonly reported "starvation diabetes," which, in the opinion of some, is caused by an increased resistance to the effect of insulin (24).

The findings of this study suggest a possible clinical application. Brittle diabetics, subject to recurrent symptomatic insulin reactions, may possibly benefit from eating ketogenic diets. Another intriguing speculation concerns the amelioration of epilepsy in children treated with ketogenic diets. No satisfactory explanation for the beneficial effect had been offered in the past. Possibly, cerebral adaptation to the utilization of ketones renders the epilepsy-prone child less vulnerable to the potentially irritant sequels of a fall in glucose concentration.

\section{ACKNOWLEDGMENTS}

This study was supported in part by National Institutes of Health grant 1T01-AM-05557-01.

\section{REFERENCES}

1. Owen, O. E., A. P. Morgan, H. G. Kemp, J. M. Sullivan, M. G. Herrera, and G. F. Cahill, Jr. 1967. Brain metabolism during fasting. J. Clin. Invest. 46: 1589.

2. Drenick, E. J., L. A. Alvarez, and G. C. Tamasi. 1971. Resistance to symptomatic insulin reactions after fasting. Clin. Res. 19: 186.

3. Yalow, R. S., and S. A. Berson. 1960. Immunoassay of endogenous plasma insulin in man. J. Clin. Invest. 39: 1157.

4. Sunderman, F. W. 1953. Further modifications in the measurement of blood glucose. Am. J. Clin. Pathol. 23: 193.

5. Schotz, M. C., G. M. C. Masson, and I. H. Page. 1959. ACTH in zitro on release of nonesterified fatty acids from adipose tissues of adrenalectomized rats. Proc. Soc. Exp. Biol. Med. 101: 159.

6. Gibbard, S., and P. J. Watkins. 1968. A micro-method for the enzymatic determination of $\mathrm{D}$ - $\beta$-hydroxybutyrate and acetoacetate. Clin. Chim. Acta. 19: 511.

7. Sobel, C., and R. J. Henry. 1957. Determination of catecholamines (adrenalin and noradrenalin) in urine and tissue. Am. J. Clin. Pathol. $27: 240$.

8. Von Euler, U. S., and R. Luft. 1952. Effect of insulin on urinary excretion of adrenalin and noradrenalin. Studies in ten healthy subjects and in six cases of acromegaly. Metab. (Clin. Exp.). 1: 528.

9. Smith, A. L., H. S. Satterthwaite, and L. Sokoloff. 1969. Induction of brain $\mathrm{D}(-)-\beta$-hydroxybutyrate dehydrogenase activity by fasting. Scicncc (W'ash. D. C.). 163: 79.

10. Hawkins, R. A., D. H. Williamson, and H. A. Krebs. 1971. Ketone-body utilization by adult and suckling rat brain in vivo. Biochem. J. 122: 13.

11. Williamson, D. H., M. W. Bates, and M. A. Page, and H. A. Krebs. 1971. Activities of enzymes involved in acetoacetate utilization in adult mammalian tissues. Biochem. J. 121: 41.

12. Openshaw, H., and W. M. Bortz. 1968. Oxidation of glucose, acetoacetate and palmitate in brain mince of normal and ketotic rats. Diabetes. 17: 90 .

13. Rolleston, F. S., and E. A. Newsholme. 1967. Effects of fatty acids, ketone bodies, lactate and pyruvate on glucose utilization by guinea-pig cerebral cortex slices. Biochem. J. 104: 519.

14. Ide, T., J. Steinke, and G. F. Cahill, Jr. 1969. Metabolic interactions of glucose, lactate and $\beta$-hydroxybutyrate in rat brain slices. Am. J. Physiol. 217: 784.

15. Davidson, P. C., and M. J. Albrink. 1965. Insulin resistance in hyperglyceridemia. Metab. (Clin. Exp.). 14: 1059.

16. Tzagournis, M., and T. G. Skillman. 1970. Glucose intolerance mechanism after starvation. Mctab. (Clin. Exp.). 19: 170.

17. Foster, D. W., 1967. Studies in the ketosis of fasting. J. Clin. Ini'st. 46: 1283.

18. Balasse, E. O., and R. J. Havel. 1971. Evidence for an effect of insulin on the peripheral utilization of ketone bodies in dogs. J. Clin. Inz'est. 50: 801.

19. Bieberdorf, F. A., S. S. Chernick, and R. O. Scow. 1970. Effect of insulin and acute diabetes on plasma FFA and ketone bodies in the fasting rat. J. Clin. Invest. 49: 1685 .

20. Gottstein, U., W. Müller, W. Berghoff, H. Gärtner, and K. Held. 1971. Zur Utilisation von nicht-veresterten Fettsäuren und Ketonkörpern im Gehirn des Menschen. Klin. Wochenschr. 49: 406.

21. Wiener, R., H. J. Hirsch, and J. J. Spitzer. 1971. Cerebral extraction of ketones and their penetration into CSF in the dog. Am. J. Physiol. 220: 1542.

22. Eisenberg, S., and H. S. Seltzer. 1962. The cerebral metabolic effects of acutely induced hypoglycemia in human subjects. Metab. (Clin. Exp.). 11: 1162.

23. Owen, O. E., and G. A. Reichard, Jr. 1971. Human forearm metabolism during progressive starvation. J. Clin. Invest. 50: 1536.

24. Genuth, S. M. 1966. Effects of prolonged fasting on insulin secretion. Diabetes. 15: 798. 